Henrik Mattsson, Uppsala

\title{
Geographies of unruly innovation
}

\begin{abstract}
While it has been convincingly shown that innovation is vital to the long-term economic success of localities, regions and nations, much is lacking in terms of knowledge about the sophisticated and unruly spatial processes involved in innovation that take place fragmentarily and unevenly in the grain of territories. This paper discusses how Torsten Hägerstrand's time-geography may contribute towards deepening our understanding of such geographies of "unruly innovation". Keywords: unruly innovaion, time-geography, grain-geography, local vs. global, innovation, innovation geography
\end{abstract}

\section{Introduction}

The economic landscapes in which we live our daily lives are constantly changing. New industries emerge, others become obsolete. Old ways of (making a) living are at risk of being contested and phased out. Some regions prosper while others stagnate. An increasingly common response to this reality consists of public policies that aim not at protecting the status quo (e.g. by imposing tariffs and other trade barriers), but rather at making economies more prone to change and more capable of dealing with it. The underlying logic of this policy agenda is that competitiveness comes from creative self-destruction - that is, from upgrading ones advantages ahead of time instead of protecting what used to work. We can therefore note, within policy communities around the world, a sharp attention to the phenomenon of innovation, often coupled with a liking of so-called high-technologies, e.g. biotechnology, and engagements with systemic and spatial frameworks, e.g. clusters or innovation systems. "E. g. growth is increasingly related to the capacity of regional economies to change and innovate. Regions and cities have become the primary spatial units where knowledge is transferred, innovation systems are built and competition to attract investments and talents takes place." (European Commission on Regional Innovation, Internet: http:// ec.europa.eu/enterprise/policies innovation/ policy/regional-innovation/index_en.htm, 10.11.2009). “

The trouble of the matter is that innovation is an inherently hard thing to govern, particularly in geographical terms. Known success-stories often run deep with randomness and specificities of time and place. Indeed, the distribution of winner- and loser-regions in the global economy often seems just as well explained by chance, contingency and path-dependence, as by differences in specific innovation policies. At the very least, it is clear that winning formulas are not easily moved from one context to another. As is described in more detail in the next section, the problem has to do in part with the complexity of innovation and in part with its highly contingent nature which means that each of the several solid innovation theories that are at our disposal only apply under certain conditions.

In fact, innovation scholars and policymakers are living with the following dilemma: on the one hand, it has been convincingly shown that long-term economic success of localities, regions and nations to a high degree depends on their ability to innovate (LUNDVALL 1992; EdQuist 1997; Malmberg/Maskell 1997; BRACZYK et al. 1998; MASKELL/MALMBERG 1999; LUNDVALL 2005), on the other, it is proving hard to find solid empirical evidence in support of claims to policy control over success factors or local innovation effects. There are several studies that satisfyingly makes sense of innovation-processes in retrospect. Yet it remains difficult to apply these historical experiences to emerging situations. When it comes to innovation-based expectations for economic development it is arguably with the term innovation as it were with the term cluster 
in Martin and Sunley's critique of the concept: "Seductive though the cluster concept is, there is much about it that is problematic, and the rush to employ 'cluster ideas' has run ahead of many fundamental conceptual, theoretical and empirical questions". (MARTIN/SunLEY, 2003, 1)

This paper argues three things. First, that some of the most important conceptual, theoretical and empirical questions that we have 'run ahead of' concern the spatiality of innovation. Second, that working with these questions requires a sophisticated framework for analyzing grain-geography. Third, that Torsten Hägerstrand's time-geography offers a strong foundation for developing such a framework.

Following a brief methodological note, the next section further discusses the abovementioned "unruly innovation dilemma". In particular, it identifies more precisely the questions of interest for the present paper, and motivates the assumption that time-geography can be a vital part of answering these questions. Sections 3 and 4 provide an introduction to timegeographical theory and notation along with a critical analysis and suggestions for upgrades and additions. Section 5 discusses implications for everyday research. Finally, section 6 concludes these exercises and discusses the work that lies ahead.

\section{Methodological note}

This paper is mainly theoretical. However, it is also undeniably the result of what might best be described as a long-lasting whirlwind of deduction and induction - its proposals and propositions are the fruit of a long-term research-process and therefore naturally draws on manifold firsthand and secondhand empirical observations as well as abstract argumentations of both my own and others' making. Hence, this paper does not include any new empirical material per se, but it draws on a number of examples from my previous research (MATTSSON 2006; 2007a,b; 2009).

\section{The unruly innovation dilemma and grain-geography}

The issue of interest here is the usefulness of time-geography in contemporary innovation study. Most of the following is therefore focused on the time-geographical notation and its theoretical and empirical applications. However, for time-geography's value to be fully appreciated, the context in which it is to be applied - the unruly innovation dilemma - must be further introduced. Given the large number of scholars and policy makers that currently are interested in innovation, it is problematic, and often provocative, to discuss the unruly nature of innovation without taking into account the many roles innovation can play in economic development and broader societal processes, or the significant variety of innovation policies. At the same time, it is impossible to properly represent this vast diversity. WOLFE (1994, 406) notes: "...there can be no one theory of innovation, as the more we learn, the more we realize that 'the whole' remains beyond our grasp", and so it is also with the notion of unruly innovation.

Based on this insight, this section makes no effort to directly discuss how its content relates to specific cases of innovation theory or policy. Instead, the following attempts to provide as clear a picture as possible of:

- how the paper understands innovation;

- what it means by unruly innovation;

- why such a notion motivates further studies related to the geography of innovation processes, and;

- why time-geography is helpful in this context.

There is no need to in any length explain why innovation is a major economic force. This process, in its many forms, has been widely recognized as being: (i) at the heart of the explanation of post world war one economic growth, and by extension; (ii) one of the fundaments of economic life as we know it. Whether we are talking about new technologies, new products or new practices, it stands clear that one of the most potent forces behind economic growth lies in new (and better) ways of carrying out day-today economic activities (KLINE/ROSENBERG 1986; STORPER/WALKER 1989; LUNDVALL 1992; EDQUist 1997; MALECKI 1997; COOKE/ LEYDESDORFF 2006; DICKEN 2007).

While there is little disagreement as to the importance of innovation for economic systems, it is still unclear how different parts of the ge- 
ography of such systems are affected and what they should do about it. Innovation takes place throughout the global economy, although obviously not in a very even manner, and it should therefore not be understood as only concerning certain places or actors. However, most localities and public economic actors have some sort of engagement with innovation and are therefore good objects for innovation study. Here, innovation is studied in connection to economic development policy, but this particular point of departure does not serve to say anything about the inherent need or legitimacy for such policy. The motive for this focus is twofold. First, public innovation policy will most likely be a given part of democratic societies for a long time to come and research about public efforts to control and harvest innovation is therefore well motivated, whether our a priori assumptions are in favor of such efforts or not. Second, and more importantly, the events and processes that take place when territorially bounded policy-makers attempt to influence global innovation are quite informative about the spatial "nature" of innovation also in broader terms.

Innovation policy is facing significant challenges. Even if we would somehow find a general recipe for making an economic system creatively destructive and proactive rather than comfortable and habitual, we would still be stuck with the fact that any "ruler of innovation" is in practice always limited to a given territory, while innovation processes, on the other, in today's globalized economy have little respect for borders and distance. Since innovation is anything but a simple, granular or linear process, the geography of innovation must not be assumed to be simple, contained or evenly diffused. Innovation inherently involves introducing something into a societal context and is therefore truly inseparable from time and space. It takes place when inventions or other novelties are introduced and put to use in a complex system of actors, competences, other inventions, institutions, and there is resistance, inertia and rejection involved. This is a complex process to make sense of. However, despite their complexity, innovation processes unfold as observable phenomena in time and space - e.g. new technology, competence, firms, markets, laws and infrastructure. We have, in a sense, geography working for us as a sorting mechanism, but also in relation to geography, innovation should be considered in- herently unruly. The unruly nature of innovation can be divided into four dimensions that relate both to the "general recipe" and to space: (i) unpredictability; (ii) complexity; (iii) destructiveness, and; (iv) spatially promiscuity.

For those interested in predicting or governing innovation, it is of course vital to understand how policy-design affects its rate, quality and direction. The first aspect of the unruliness of innovation, however, is that it is more or less impossible to know beforehand where innovation might take us. In retrospect, we can often make significant sense of innovation processes in terms of important actors and inputs, but to translate innovation biographies into a satisfactory ability to predict what current conditions and actions may yield in the future is a completely different matter. Innovation by definition changes the rules of the game. Although there are definitely successful economic strategies that build on prediction, this is a significant challenge. Secondly as LunDVALL (2005) and others have noted, innovation processes are composed of a wide range of inputs and influencing (f)actors, which makes it hard to understand success and failure. Everyday life is full of examples - such as seatbelt usage, - which point to the essence of this observation: in spite of sophisticated technology, legislation and clear scientific evidence that new ways are better than old, accomplishing change is a much more complex matter than desiring it. Thirdly, innovation has a tendency to destroy the institutions that have been set up to govern it. It has a destructive side to its creativeness. Often, innovation is a response to the system that has been set up to govern it, which, although it is sometimes the desired outcome, can also render the system inefficient or counterproductive.

Due to these factors, it is unrealistic to talk about a general recipe for innovation. It is also unreasonable to assume that innovation will behave according to things like distance-decay models. Innovation is a spatially promiscuous phenomenon. In the global economy, most industries and hence most innovation systems span a multitude of territories and this means that innovation processes are rarely contained within, or faithful to, simple spatial units. At the other end of the spectrum, there will be pockets of rejection even within local sites. Indeed, it is rule rather than exception that inno- 
vation processes fall in and out of parts of the specific territories that we are interested in as opposed to mainly taking place evenly within their borders (DiCKEN 2007; MATTSSON 2007). This has different meanings for different stakeholders depending on the geography of their operations and interests. Public innovation policy makers, who can only influence one territory, are likely to struggle where multi-national corporations (MNC), who operate across territories, might find a source of power and competitiveness.

Note well that the notion of unruly innovation does not mean that we should stop trying to understand or govern it. Innovation is spatially promiscuous but it is at the same time highly influenced by geography. We know at this point that location matters; we know that success factors sometimes are "in the air" (MARSHALL 1890); we know that proximity is important (GERTLER 1995; GRABHER 2002; OWEn-SMith/Powell 2002; Bathelt et al. 2004; StORPER/VENABLES 2004). Especially with regards to the latter references we know in detail some of the major mechanisms involved. However, contemporary economic geographical theory seems to have a hard time dealing with innovation without erasing the complexity of the various rationales and geographies that affect it. Geography is generally reduced to four or so categories on the localglobal spectrum or even further reduced to a local-global dichotomy in which local is used as a simple proxy for geographical effects - for example, local (as opposed to global) stands for shared tacit knowledge (in contrast to BATHELT et al. 2004); local means more interaction; local represents similar culture (in contrast to Wenger 1999; AMIN/COHENDET 2004; AMIN/ROBERTS 2006). The following argues that when it comes to explaining anomalies, contradictions and outliers to the general predictions, things intimately involved with innovation processes, we need a different kind of geographical language - one that can exist without scale and that is based in the grain.

One could understand such a language as being more detailed, but it should not be confused with some sort of micro-level. The point is to not at all think about geography in terms of scale. The grain serves instead as the "atomic" level. In this language, a person in London can be connected to a person in New York though a broad variety of geographies and its distance concept must therefore be separate from its scale concept. However, such geographies are connected to each other, and grounded, in a sense, in the grain. For example, the internet socket exists in time and space, there are a certain numbers of flights at a certain price per day between London and New York, one person goes for lunch when the other wakes up. Even seemingly "free-flowing" global interactions are grounded in time and space.

The grain-geographical perspective has two main advantages over aggregate categories for meeting the research challenges posed by unruly innovation. First, it allows for a greater variety and heterogeneity which allows for more of the important couplings and mechanisms that underpin innovation to be seen. Spatial promiscuity may seem random at the aggregate level but in the grain quite straightforward mechanisms facilitate or hinder aspects of stickiness and escape (see for example Dicken/Malmberg 2001; BAthelt et al. 2004). In a sense, the grain is a laboratory in which the actions of innovators give away clues about innovation processes, not only in the sense that they tell us something about how innovators interpret their involvement in innovation processes but also in terms of how actors shape their surroundings. Aggregate levels can of course also be seen as laboratories, but for the same reason that they can be useful in other instances, namely that they show larger trends rather than messy pictures, these aggregates tend to bunch together phenomena and mechanisms that in the context of innovation study really ought to be kept apart in the analysis.

Second, the time-space grain can in itself be understood as a key organizing mechanism. We know that many of the balances (e.g. exploration versus exploitation (GREVE 2007, 945-946), combinations (e.g. entrepreneur plus scientist, ELIASSON/ELIASSON 1996) and contradictions (e.g. "dig your own pit deeper" incentives versus cross-disciplinary research, MATTSSON 2006) involved in successful innovation are hard to achieve in most organizations (e.g. universities, firms, industries, government agencies). Yet these may be totally feasible in a small locality or, in other words, in a grain-geographical site. To understand the workings of such a site is therefore just as important as it is to understand the institutions of nations or the organizational structure of a 
MNC or a university - both in terms of its internal mechanisms and in terms of its interface with other sites. However, the high degree of complexity that provides the value of this perspective swings both ways. In order to make sense of the swarming world of grain-geography we need strong tools for coping with complexity and paradoxes - both conceptually and empirically - without aggregating or erasing them, which is where time-geography enters the picture.

\section{Time-geography}

The following section serves to introduce the reader to time-geography. It focuses on Torsten Hägerstrand's writings, since these points to several avenues that are different from those actually chosen by researchers over the last half century. It is an intricate task in 2009 to not confuse historical usage, which is often mechanistic and simulation-focused, with true theoretical potential.

Time-geography may be most commonly associated with the time-space matrix - a kind of map that displays things not only in space (the $y$ and $x$ axes) but also in time (the $\mathrm{z}$ axis). Indeed, much of the novelty of the theory did, at the time of its conception, lie in the way Hägerstrand handled mapping - or, one could argue, geography itself (PRED 1977; GREGORY 2000). He took a point of departure in the grain (e.g. people, things and ideas) at a time when most geographers started their maps by outlining the borders of a region, and he gave time and space the status of being resources as opposed to being mere media. Thanks to these seemingly trivial changes in focus, Hägerstrand was able to formulate a theory that in terms of its capacity to aid grain-geographical thinking and analysis has several advantages over other approaches.

In a sense, time-geography is grain-geography. All action and all events take place bounded in time and space and are formed by what Hägerstrand calls the "condition of corporeality" (HÄGERSTRAND 1985). Everything has either a body or is embodied; nothing exists outside of time and space. Because of this ubiquitous condition we can, theoretically at least, assign coordinates to all things, whether they are stones, technologies or ideas. This does not mean that things may have only one set of co- ordinates - an idea, for example, can be shared and therefore have two or more coordinates (exist in two or more bodies). What it means is that even the seemingly intangible leaves traces and is expressed in time and space ideas reside in brains, books and works of art. Yet time and space are not only media or containers but rather vital components of social phenomena. They are resources needed for the creation of events and they are objects of desire that lead to struggles between individuals.

In time-geography any process can be understood as a gathering of existents in time and space. To make sense of existent-gathering and the condition of corporeality, or, in other words, to understand the rules of time-space existence and interaction, Hägerstrand formulated several concepts and constructed the time-space matrix. The following presents parts of the resulting notation.

To begin with, Hägerstrand identified three types of existents: (i) physical objects and states; (ii) mental states, and; (iii) cultural products. The first type includes inorganic and biological existents as well as all artifacts. The second type includes things like knowledge, perception, memories and emotion. In the third category we find stories, myths, and mathematical theorems (HÄGERSTRAND 1985). As is further discussed below, these categories are arguably somewhat dated. The point of introducing the concept and its types here is that existents are the fundamental study object of time-geography. The time-geographer tries to explain events and non-events by studying existents as they move through time and space. Of course, existents do not float around randomly. There are forces that affect their speeds and directions. For example, human actors play a significant role as gatherers of existents.

The second fundamental concept in time-geography is project. It is assumed that all human beings are driven by a more or less strong desire to shape the future. In order to do this we set up projects and try to accomplish them (HÄGERSTRAND 1982). In time-geography, projects are all about control over existents, time and space or as HÄGERSTRAND $(1986,43)$ put it: "struggles of power over the entry of phenomena and events into space and time". Theoretically, a project can be of any scale and scope, from conducting a single experiment in the laboratory to mapping the human genome, 
and it can be driven by (m)any rationale(s), from altruism to narcissism. However, just as existents do not float around undisturbed, projects are subject to a rather harsh set of restrictions; in the time-geographical notation such factors are called constraints.

There are three types of constraints that influence projects: (i) capability constraints; (ii) authority constraints, and; (iii) coupling constraints (HäGERSTRAND 1970). As the term suggests, capability constraints have to do with the limits of what individuals can do. This includes all types of biological and intellectual limitations that come with the human body, for example the need to sleep and eat. Authority constraints are instead limits of norms and culture. There are a lot of things that we are able to do and understand that we are able to do but that we still do not generally do, even if it would be beneficial to us, because of formal and informal institutions - all such limits are termed authority constraints in the time-geographical notation (for a comprehensive discussion on this see HoLm et al. 1989). In relation to classical economic analysis we can note here that the notion of capacity constraints and authority constraints are incompatible with notions of perfect information or rationality. In time-geography, decisions are always situated. Coupling constraints, finally, are limits to the formation and duration of what Hägerstrand calls bundles. A bundle is a gathering of existents in time and space. In principle, it is possible to apply the bundling concept to any event or process but a certain degree of aggregation is usually necessary. To take a practical example - learning - we can understand this process as requiring the bundling of a person and a piece of knowledge (this knowledge being in a body of some sort). With this level of aggregation we can use the bundling concept to make sense of the role played by for example networks, learning institutions, and knowledge milieus, in terms of their impact on bundling, duration and repetition and vice versa. The point of the bundling concept is to better understand how space and time - and particular aspects of these things, such as proximity, duration and timing - matter to the taking place of events. GREGORY (2000) explains this in the following manner: "Hägerstrand's ideas emphasize the continuity and connectedness of sequences of events that take place in situations bounded in time and space and whose outcomes are thereby mutually modified by their common localization". So, the bundle concept serves to say that common localization of existents is essential for the formation of events and phenomena. Bundles are characterized by their extension in space and their duration in time. If we connect this to aforementioned concepts we see that projects are really about bundling existents and that this process is governed not only by capacity and authority constraints but also by the rules of bundling itself - coupling constraints.

One of the strongest coupling constraints has to do with the limitations imposed by logistics - or to put it simply: the fact that it is costly and time-consuming to move stuff through space. The construction of physical and organizational infrastructure is a common way to overcome this constraint. Such infrastructure can of course be seen as a kind of bundle but due to its, in this context, relatively long duration and more or less permanent localization, it makes more sense to talk about it as some sort of bundling framework. This leads us to the last two concepts of this presentation: station and domain. A station is a sort of spatial fix point. Typically it is part of the built environment, like a home, an office, a building or a laboratory. Stations get their name from the fact that they always stay put in the time-space matrix. They enter time, the z-axis, when they are built and they exit this axis when they are destroyed but their $\mathrm{x}$ and $\mathrm{y}$ coordinates are permanent and stable during their existence. In time-geographical analysis, stations are important for understanding, among other things, repetitive bundle formation. Domains, finally, are segments of time-space over which a certain actor possesses significant control in terms of entry and exit of existents - and by extension, in which this actor can also influence or even create authority and coupling constraints. Just as stations are often important for the successful completion of projects, so is the security of operation that domains provide. As we can see, the above concepts are overlapping, and sometimes quite fuzzy. This is as it should be. The notation is no strict rule-book. It is a notation - inspired by the language of musical composition. Its purpose is to guide our analyses and to help us communicate our conclusions, not to function as a deterministic sequencer of input data.

As should be clear from this section so far, time-geography offers a detailed notation for 
handling grain-geographical mapping of innovation processes. We can think of both empirical and conceptual mapping applications. It would for example be possible to study the formation of innovation environments (stations and domains) and the constraints and projects that control the dynamics of them. The building of such environments may inform us about the sometimes rather triviallooking challenges and issues that are in fact important for the success of innovation projects. Such factors may be quite general between contexts since they are part of the common condition of corporeality and would therefore offer strong theoretical explanations. We could also use the time-geographical notation to study innovation landscapes - the practices of innovators and the process of innovation in itself may be very hard if not impossible to access and study - but the milieus (stations, domains, networks and bundles) that innovators build in order to aid their endeavors are realistic study objects.

However, it is arguably in the conceptual or, one might say, ontological spectrum of Hägerstrand's theory that contemporary economic geography may find the largest treasures. The time-geographical notation offers radically new ways of thinking about the taking place of innovation processes and while empirical studies are important, it would be a repetition of old mistakes to downplay the conceptual promise of time-geography by restricting it to detailed analyses of particular events and flows. What is needed is rather an even more developed and upgraded time-geographical notation to match contemporary theory and issues.

\section{Upgrading time-geography}

The main advantage that time-geography holds over other approaches is that it provides much needed structure to the messy reality of grain-geography. It allows us, in other words, to penetrate geographical black boxes and access fundamental processes that are assumingly more stable and general over time and space than the patterns and events commonly associated with, and contributed to aggregates like regions and localities. In its present state, the comprehensive theory of time-geography is already quite helpful with regards to the abovementioned research agenda. However, while it captures some things really well there are oth- ers that it misses. For example, its current main strength is its aptness when it comes to thinking about, asking questions about, and mapping objects and bodies in time and space. To a lesser extent it is useful for capturing intentions and possibilities. What time-geography in particular tends to miss, are the things going on in relations between existents. The framework implicitly states that these things are important in that it recognizes the vital impact of entry and exit to bundles and the power struggles associated with that, but it does not explain well enough the dynamics in bundles and of bundling. In my experience, it also tends to keep the researcher too close to initially studied existents, and thereby blinded to the bigger picture and the sprawling networks to which these existents are merely an accesspoint. While the relations-issue is an example of shortcomings due to historical usage, the latter is an example of challenges posed by inherent characteristics of the framework.

Time-geography as originally formulated by Hägerstrand is arguably a very broad attempt to capture any geographical process. Yet, as mentioned, the framework has been rather narrowly used. Especially this is true in the sense that the conceptual side, although strong in the beginning, has been more or less neglected in the later development of time-geography. This section serves to address mainly this issue by introducing some new concepts. It also discusses, briefly, how we may apply the here mentioned lessons when using time-geography in everyday research. The following identifies current weaknesses but should really be seen as a specification of potential areas of future contribution.

\section{Becoming/lingering}

One problem with time-geography is that existents tend to be treated as if they have incorruptible identities or properties. An existent is essentially the same when it leaves a bundle as when it entered it. Although the time-geographer would never dismantle a bundle by playing time backwards, this way of treating existents as separate and more or less unchangeable entities does tend to limit the scope of the analysis. Thanks to other academic and philosophical frameworks - like actor-network-theory - we now know that it can be helpful to understand bundling not only as a temporary connection of different pieces but rather as assemblages in which constituting elements are 
affected by each other to the extent that they receive new properties (DELEUZE/GUATTARI 1988). The concept of becoming is arguably particularly relevant in this context. This term serves to say that existents should be understood as being in constant flux and open to corruption by the elements they enter into composition with, not only for the duration of this composition but also afterwards - and, one could argue, before even entering into it (through anticipation). One aspect of this is that things should be understood as having some sort of extended time-space existence they reach into the future and drag out in the present after they have physically left. For the latter, a concept like lingering may be helpful. This serves to denote intangible properties of an existent, bundle, station or domain that are the result of a recent coupling.

\section{Affect}

In time-geography, bundles are the results of attempts by actors to realize their projects within a framework of constraints. While this goes far in explaining grain-geographical processes behind actions and events it misses what we would refer to as non-human agency and also much of non-rational behavior. It is reasonable to assume, in line with Hägerstrand, that human beings desire to control their future and take action with a point of departure in this desire, but it is also reasonable to assume that within the carrying out of projects, humans and constraints are not the only influencing factors. In the time-geographical model, there is in a sense a balancing act between, on the one hand, human desire to control the future, which functions as a creative force and, on the other, the constraints which function as the limits of this creativity. However, this excludes the element of non-human creativity or non-human inspirations that inevitably enters the calculation as soon as we abandon perfect rationality. Of course, a place is in a sense just sticks and stones, bricks and mortar, but as a site for human action we must understand it in a broader sense. The existents that make up a place are easily mapped in the time-space matrix, but what about things like nostalgia, sense of home and so on. How do we understand and map the things that make a scientist stay in the lab for weeks, sacrificing family and health? They are evidently there, judging from actions and behavior. But where - and how do we treat these things from a time-geographical perspective?
In some areas, time-geography offers clear rules, in particular when it comes to constraints, but it remains unclear how objects change each other when they enter into composition with one another in the bundles. Affect here serves to account for the thing that happens when an actor enters into composition with a place and motions are created that are not of the place or the actor but of the coming together of the two (for an excellent example of how affect should be understood here, see the discussion about non-human charisma in LORIMER 2006). Affect is so to say a motioncreating link between human and environment, a link that evolves over time, and indeed, from time to time transcends the borders of the human identity and its natural environment, to dissolve the social into nature and vice-versa (WhATMORE 2002). One example that probably everyone who has interviewed an inventor, scientist or entrepreneur, can relate to, is the fact that these people often have a special outlook, drive or hunger - in fact, some might say that they are all at least a little bit crazy - which comes from their relationship to a thing, idea or project and which has a significant impact on the choices they make (but is distinctly different from what we would term rationality). Even though it is not always significant to go into deep philosophical reflection concerning the relationship between for example a scientist and an elusive study object, it is almost always relevant to acknowledge that this relationship is not marginal and to have a concept, like affect, that at least begins to handle this insight.

\section{Implications for everyday research}

As noted, the actions of those involved in innovation processes and the way they shape their environments may offer an alternative access-point for studies about the geography of innovation processes. This sub-section will briefly introduce three things that may be helpful in practically carrying out the kind of research that the present paper argues for. In a sense these can be seen as empirical accesspoints but can also aid abstract thinking about the geography of innovation.

The main access-point into grain-geographies of innovation is at the people and things involved in the innovation process of interest. Depending on the body we chose and other 
considerations, we may decide to use a number of methods (e.g. interviews, observation, GIS) to let it guide us through the innovation landscape and show us some of the other existents that it bundles with. In case we are following a person we must in addition to this basic exploration also try to put ourselves in the situation of the innovators: What kind of landscape are they looking at? How do they interpret their surroundings? We must also ask: What do their reactions to this landscape, in particular their efforts to change aspects of it, tell us about the nature and spatiality of innovation?

The second access point is in biographies (of people) and/or trajectories (of things). While the selected body may give us plenty of information about the geographical and virtual landscapes in which it moves, connects and communicates - even relative long-term observation only covers a segment of its life. The construction of biographies and the mapping of trajectories can help us understand more about current events than a simpler geographical analysis would, and perhaps even make predictions about future probabilities. Often trajectories are steered by preexisting conditions and networks that can be found in biographies. In general, the goal should be to fully use the time-dimension of time-space to merge aspects of path-dependency, networks, and time-space convergence into a powerful framework of event-analysis.

Events, finally, form the third access-point to grain-geographical study. When using events, the point is to do the opposite of the trajectory analysis, namely to shorten the time-perspective, and only look at a snap-shot. Detailed and contra-factual event-analysis can be a powerful starting point for understanding how things: (i) arriving too soon; (ii) too late; (iii) already being there (in the way); (iv) arriving just in time, or; (v) failing to arrive, created the specifics of the event and to, in turn, use this information to analyze processes of entry and exit to the site under study.

Gathering information about grain-geographies through these access-points, and analyzing it in relation to the above-introduced and modified time-geographical notation is no easy task not the least so in terms of the time it takes. For the same reason, it would require an additional paper just to exemplify in any depth the different steps and stages of putting the suggested framework into practice. As much as the present paper would like to further develop on its proposals it now therefore moves on to the final section - hoping that the above has at least given some guidance to how we might use time-geography to think about and analyze grain-geographies of unruly innovation.

\section{Conclusion}

In the opening segments of his thesis, Hägerstand talks about something that he terms "the one-point society" (HÄGERSTRAND 1953). This represents the world as it would be if time and space were to become ubiquities - equally available to everyone. In the one-point society, geography has passed on and the cause of death is clear: If everything in the world is equally close to everything else, the terms here and there are synonymous and location obsolete. Hägerstrand predicted that something like this would come into existence "when television sets can be used not only to receive but also to send information" (HäGERSTRAND 1953) - or as we might put it, with the Internet. 50 years later, technology has indeed wreaked havoc in the time-space matrix, but instead of witnessing the death of geography, we have seen the rebirth of the local. August Lösch, 10 years older than Hägerstrand, was the better prophet of the two when he claimed: "only because our world is restricted [...] can we, in our finiteness, endure at all" (LösCH 1954).

The fact that Hägerstrand's prediction was wrong does not cast a shadow on his capability as a social scientist, on the contrary, the prediction in itself says quite a lot about how relevant his thinking about innovation and technology was, long before the major processes of technology and innovation driven globalization that we now take for granted had come into effect. He understood early on that technology would change the world radically, not only in terms of providing new things and technical possibilities but, more importantly, by changing the very relationship between man, time and space. His prediction concerning the sending/receiving television sets reveals a notion of technological change impacting the very fabric of everyday life - affecting local society by changing fundamental grain-geographical mechanisms for social interaction, network creation and information exchange. It is fascinating to imagine that it was Hägerstrand's 
unique way of thinking geographically, that led to his strong conclusions about innovation and technology.

Today, economic geographers are struggling to make sense of the relationship between change and geography. How do we secure local returns on investments in innovation? Will investments made in one of the many territories to which an innovation process is connected leak out of that territory and, if so, will it actually trigger processes that compete directly with the possibility of the "home-territory" to reap the fruits of the investment? Or will it lead to something that is good for everyone in the long term, through natural market/trade mechanisms? Is there such a thing as a "local innovation environment", which could be damaged by outsourcing and globalization (compare STORPER 2009)?

Hägerstrand's time-geography is relevant to the key questions of contemporary economic geography, but while there are probably few economic geographers who have not heard of timegeography or would recognize a time-space matrix when they saw one, Hägerstrand's wider contribution to the way we can approach and think about geography itself is conspicuous by its absence. As noted above, we now sooner use concepts like region and local than time-space trajectory and bundle, which in essence means that our approach to what a geographical question is, has more in common with the view that Hägerstrand was trying to change than with the alternative he introduced. This is quite ironic if we consider that the research problems Hägerstrand engaged with is strikingly similar to those that presently fascinate a vast number of economic geographers worldwide. While innovation studies now holds the centre stage, one of geography's earliest and perhaps most helpful theories for thinking about the relationship between innovation, society and geography is all but absent from that research.

This paper calls for economic geographers to reintroduce time-geography into innovation research and points to some of the rewards of doing so. At the same time, however, it recognizes that this is not simply a matter of dusting off an old text and starting to think differently. As parts of the present paper shows, time-geography is significantly misaligned with regards to current issues and insights. Before the promise of timegeography can be considered fulfilled, three things are needed. First, we need more grain-ge- ographical research per se, with or without timegeography. Not mainly because we need more information about what is going on in the grain but because we need a more sophisticated way of asking geographical questions - which in turn will require more sophisticated tools for empirically answering them. Economic geography has lately won itself a new and better place among the economic disciplines precisely by demonstrating that the economy is indeed a geographical animal and much promising work is currently being done to produce even more sophisticated understandings of the local/global relationship and interface. These efforts would be helped by a coherent theory of grain-geography. Such a theory would, in turn, depend on something like time-geography for structure.

Second, we need conceptual development of the type suggested in the preceding section. Timegeography can only be successful in contemporary economic geography if its conceptual side is strong and up-to-date. Its true potential is in the way it may help us formulate questions or think about processes, not in tracking these processes per se - many of the things that we are interested in as innovation-researchers are invisible or intangible, and even if they are not, they are in many cases ethically un-researchable, which is why we must always strive to find ways to build strong theory without direct observation.

Finally, we will need solid empirical studies based on lessons from the first and second points that would allow us to further adjust the new time-geography. Should this broad project succeed, as outlined here or in other forms, it would enrich economic geography in part by leading to new insight, in part by connecting existing pieces of theory, and in part by adding dimensions to aggregate concepts.

\section{References}

Amin, A./Cohendet, P. (2004): Architectures of knowledge: Firms, capabilities and communities. Oxford.

Amin, A./Roberts, J. (2006): Communities of practice? Varieties of situated learning. Durham.

Bathelt, H./Malmberg, A./Maskell, P. (2004): Clusters and knowledge: Local buzz, global pipelines and the process of knowledge creation. In: Progress in Human Geography, 28, 31-56.

BraczyK, H.-J./CoOKe, P./HeIdenreich, M. (1998) (Eds.): Regional innovation systems. London: 
CoOKe, P./LeydesdorfF, L. (2006): Regional development in the knowledge-based economy: The construction of advantage. In: Journal of Technology Transfer, (31) $1,5-15$

Deleuze, G./Guattari, F. (1988): A thousand plateaus. London.

DiCKEN, P. (2007): Global shift. Mapping the changing contours of the world economy. London.

Dicken, P./Malmberg, A. (2001): Firms in territories: a relational perspective. In: Economic Geography, (77)4, 345-363

EDQuist, C. (1997): Systems of innovation : technologies, institutions and organizations. Cambridge.

Eliasson, G./Eliasson, Å. (1996): The biotechnological competence bloc. In: Revue d'Economie Industrielle, (78)40, 7-26

GERTLER, M. (1995): Being there: proximity, organization and culture in the development and adoption of advanced manufacturing technologies. In: Economic Geography, (70), 1-26.

GraBHER, G. (2002): The project ecology of advertising: Tasks, talents and teams. In: Regional Studies, (36)3, 245-262.

Gregory, D. (2000): Time-geography. In: Johnston, R.J./Gregory, D.P./Watts, M. (Eds.): The dicitonary of human geography. London.

Greve, H. R. (2007): Exploration and exploitation in product innovation. In: Industrial and Corporate Change, (16)5, 945-975.

Holm, E./MÄKILÄ,K./ÖBERG, S. (1989): Tidsgeografisk handlingsteori. Att bilda betingade biografier. Umeå. (Gerum rapport nr. 8).

HÄGERSTRAND, T. (1953): Innovationsförloppet ur korologisk synpunkt (translated and reprinted as 'Innovation diffusion as a spatial process' 1967). Lund.

HÄGERSTRAnd, T. (1970): What about people in regional science? In: Papers of the Regional Science Association, (24), 7-21.

HÄGERSTRAND, T. (1982): Diorama, path and project. In: Tijdschrift voor economische en sociale geografie, (73)6, 323-339.

Hägerstrand, T. (1985): Time-geography. Focus on the corporeality of man. In: The United Nations Newsletter, (8)3, 193-216.

HÄGERSTRAND, T. (1986): Om geografins kärnområde. Lund

Kline, S./Rosenberg, N. (1986): An Overview of innovation. In: Landau, R./Rosenberg, N. (Eds.): The positive sum strategy. Harnessing technology for economic growth. Washington DC, 275-306.

LORIMER, J. (2006): Nonhuman charisma: which species trigger our emotions and why? In: ECOS, (27)1, 20-27.

LuNDVALL, B.-Å. (1992): National systems of innovation. Towards a theory of innovation and interactive learning. Cambridge.
LunDVALL, B.-Å. (2005): National innovation systems. Analytical concept and development tool. Copenhagen.

Lösch, A. (1954): The economics of location. New Haven, London.

MALECKI, E. (1997): Technology and Economic Development: the dynamics of local, regional and national conpetitiveness. New York.

Malmberg, A./Maskell, P. (1997): Towards an explanation of regional specialisation and industry agglomeration. In: European Planning Studies, (5), 1-15.

Marshall, A. (1890): Principles of economics. New York.

Martin, R./Sunley, P. (2003): Deconstructing clusters: chaotic concept or policy panacea? In: Journal of Economic Geography, (3)1, 5-35.

MAsKell, P./MALMBERG, A. (1999): Localised learning and industrial competitiveness. In: Cambridge Journal of Economics, (23), 167-185

Mattsson, H. (2006): How does Knowledge production take place? On locating and mapping science and similar unruly activities. In: Baraldi, E./Fors, H./Houltz, A. (Eds.): Taking place. The spatial contexts of science, technology and business. Sagamore Beach/MA, 351-372.

Mattsson, H. (2007a): Locating biotech innovation. Places, flows and unruly processes. Uppsala.

Mattsson, H. (2007b): Mobile talent or privileged sites? Making sense of biotech knowledge worker success and mobility in Sweden. In: Social Geography, 2, 115-123.

Mattsson, H. (2009): Innovating in cluster/Cluster as innovation. The case of the Biotechvalley cluster initiative. In: European Planning Studies, (17)11, 16251643.

Owen-Smith, J./ Powell, W. (2002): Knowledge networks in the Boston biotechnology community. Unpublished working paper. Stanford University.

Pred, A. (1977): The choreography of existence: Comments on Hägerstrand's time-geography and its usefulness. In: Economic Geography, (53)2, 207-221.

STORPER, M. (2009): Regional context and global trade. In: Economic Geography, (85)1, 1-21.

STORPER, M. and WALKER, R. (1989): The capitalist imperative. Territory, technology, and industrial growth. London.

Storper, M./Venables, A. (2004): Buzz: face-to-face contact and the urban economy. In: Journal of Economic Geography, (4), 351-370.

Wenger, E. (1999): Communities of practice. Learning, meaning, and identity Cambridge.

Whatmore, S. (2002): Hybrid geographies. Natures, cultures, and spaces. London.

WolfE, R.A. (1994): Organizational innovation. Review, critique and suggested research directions. In: Journal of Management Studies, 31(3), 405-431. 